\title{
An Investment Evaluation of a RFID-Enabled Meat Supply Chain: A Multi- Criteria Approach
}

\author{
Ahmed Mohammed and Qian Wang \\ School of Engineering, Faculty of Technology, University of Portsmouth, Portsmouth, UK PO1 RDJ, 3HF
}

\begin{abstract}
In recent years, consumers have become increasingly concerned about the safety and quality of meat they purchase from supermarkets. A study by Mohammed [1] proposed a RFID (Radio Frequency Identification)-enabled monitoring system for meat supply chains to improve the traceability of meat products throughout their entire supply chain with the aim of maintaining product safety. This paper extends that work to examine the economic feasibility for the proposed RFID-enabled monitoring system. To this aim, a multi-criteria optimization model was developed. The considered criteria were minimizing the total cost, maximizing consumer satisfaction, maximizing product freshness and maximizing profits. In order to obtain Pareto solutions from the developed model, a new solution approach was developed and its results were compared to two traditional solution approaches. A case study was applied conducive to an examination for the applicability of the developed model and the performance of the proposed solution approaches. Results have proved the feasibility of the proposed RFID-enabled monitoring system in terms of economic costs in addition to the capability of the developed optimization model in obtaining a trade-off among the considered criteria.
\end{abstract}

\section{Introduction}

Meat supply chains are a methodical connotation that constitute generally from four different echelons including farms, abattoirs, retailers and consumers. They are acquainted as a network of facilities that supply livestock which is transported into intermediate and final meat to be purchased by consumers. In the last few decades, increased safety and quality concerning meat purchased by consumers has been demanded in the UK [2, 3]. This refers to particular rules that should be maintained throughout the meats' entire supply chain including feeding and health of livestock, and method of slaughtering process at abattoirs [4]; Different commitments lead to a guide to decision making when purchasing types of meat. A study by Peattie [5] mentioned that consumers spend considerable time and effort seeking out fresh food and reading food labels in order to ensure they are purchasing good quality. Implementation of the RFID technology in meat supply chains was proposed to improve product safety [1]. Such a system leads to an increase in consumer satisfaction; on the contrary, it is also subjected to additional costs that should be considered.

Multi-criteria optimization is an optimization approach that encompasses multiple criteria and rather than a single optimal solution it has a set of solutions called "Pareto optimal solutions". Pareto optimal solutions represent the compromise among multiple conflicting criteria. During the last few decades, there has been increasing use of the multi-criteria optimization (or multi-objective optimization) approach to tackle a variety of problems in supply chain network design and its operations management [6-9]. These problems can be tactical such as the facility location-allocation problem or strategic such as product quantity flows in addition to considering different criteria such as costs or profit.

To the best of our knowledge, little or no research has been presented so far investigating the RFID-enabled supply chains seeking a compromise between the benefits of the RFID implementation in supply chains (e.g. consumer satisfaction and service level) and its need for additional costs along with the supply chain network design. This paper addresses this gap in the literature. It considers the proposed RFID-enabled three-echelon meat supply chain seeking a compromise among four criteria including total cost, consumer satisfaction in terms of percentage of satisfying consumers' demand, product freshness in terms of the number of fresh meat products as a result for the proposed RFID-enabled monitoring system and profits as a fourth criterion. To this aim, a multi-criteria mixed integer linear programming model was developed to simultaneously optimize the considered criteria. To reveal the solutions from the developed optimization model, three multi-criteria solution approaches were investigated including a new developed approach, compromise programming, and Weighted Tchebycheff. The developed model and its solution methodology can be used as a reference for decision makers to evaluate the performance and the economic 
feasibility of their food supply chains in implementing the RFID technology.

\section{Related studies}

Barbarosoglu [10] developed a mixed integer linear programming model to minimize the total fixed and variable costs for a two-echelon system. The Lagrangian relaxation method was used to solve the developed model. The Same method was also used by Sadjady [11] to tackle a two-level supply chain network design problem comprising both tactical and strategic concerns. The problem was formulated as a mono-criteria optimization model to minimize total costs including transportation, lead-times, and inventory holding costs for products, as well as opening and operating costs for facilities. Selim [12] presented a multi-criteria optimization model to cope with a production-distribution planning problem in a supply chain. Fuzzy goal programming was considered to incorporate decision maker's imprecise aspiration levels. Ferrio [13] formulated a mixed integer linear programming model for configuring and optimizing the design of a multi-product chemical supply network consisting production sites, an arbitrary number of distribution centers, and customers. Tuzkaya [14] studied a three-level supply chain including supplier, warehouses, and manufacturers seeking the best products distribution plan. The authors developed a multi-objective model aimed at minimizing the total cost of inventory, warehouse, manufacturer, and penalty costs for supplier, manufacturers, and warehouses.

\section{Modeling the HMSC}

The meat supply chain under consideration is comprised of three echelons including farms, abattoirs and retailers. In this chain, livestock is supplied from farms to abattoirs to be slaughtered then transported to retailers as a packed meat. The RFID technology was proposed to trace product production at farms and abattoirs, and during the transportation from abattoirs to retailers for maintaining the safety and freshness of products throughout its entire supply chain [1]. Fig. 1 depicts the schematic illustration of the investigated supply chain.

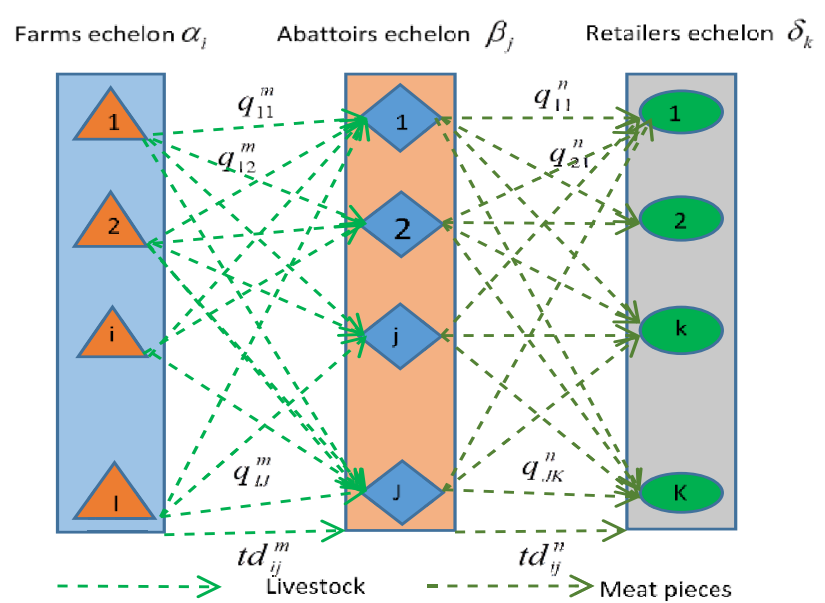

Figure 1. The schema of the investigated supply chain network.

\subsection{Notations}

To formulate the multi-criteria model, the following indices, parameters and decision variables are presented:

\section{Indices}

$I$ index used for a potential farm $i, 1 \leq i \leq I$

$J$ index used for a potential abattoir $j, 1 \leq j \leq J$

$K$ index used for a fixed retailer $k, 1 \leq k \leq K$

\section{Cost parameters}

$C_{i}^{\alpha}$ equipment and implementation cost of the RFID technology required for farm $i$

$C_{j}^{\beta}$ equipment and implementation cost of the RFID technology required for abattoir $j$

$T C_{i j}$ unit transportation cost per mile from farm $i$ to abattoir $j$

$T C_{j k}$ unit transportation cost per mile from abattoir $j$ to retailer $k$

$$
\begin{aligned}
& L C_{i}^{\alpha} \text { unit labor cost per hour at farm } i \\
& L C_{j}^{\beta} \text { unit labor cost per hour at abattoir } j
\end{aligned}
$$

\section{Parameters of capacity, demand and transportation} distance:

$C_{\mathrm{i}}^{\alpha}$ maximum supply capacity (units) of farm $i$
$C_{\mathrm{j}}^{\beta}$ maximum supply capacity (units) of abattoir $j$
$W_{v}$ transportation capacity (units) per vehicle $v$
$\mathrm{D}_{\mathrm{j}}^{\beta}$ minimum demand (in units) of abattoir $j$
$\mathrm{D}_{\mathrm{k}}^{\delta}$ minimum demand (in units) of retailer $k$
$d_{i j}$ travel distance (mile) through the first transportation link $\mathrm{m}$ from farm $i$ to abattoir $j$

$d_{j k}$ travel distance (mile) through the first transportation link $\mathrm{n}$ from abattoir $j$ to retailer $k$

\section{Labor parameters}

$R_{i}^{l \alpha}$ working rate (items) per laborer $(l)$ at farm $i$

$R_{j}^{l \beta} \quad$ working rate (items) per laborer $(l)$ at abattoir $j$

$h_{i}^{l \alpha}$ minimum required number of working hours $(h)$ for laborer $l$ at farm $i$

$h_{j}^{l \beta}$ minimum required number of working hours $(h)$ for laborer $l$ at abattoir $j$

\section{Other parameters}

$Q_{i j} \quad$ quality percentage of products transported from farm $i$ to abattoir $j$

$F_{j k}$ freshness percentage of products transported from abattoir $j$ to retailer $j$

$P_{i}^{\alpha}$ profits (GBP) per item at farm $i$

$P_{j}^{\beta}$ profits $(\mathrm{GBP})$ per item at abattoirs $j$ 


\section{Decision variables}

$q_{\mathrm{ij}}$ quantity of units transported from farm $i$ to abattoir $j$

$q_{\mathrm{jk}}$ quantity of units transported abattoir $j$ to retailer $k$

$x_{i}^{\alpha}$ minimum required number of laborers at farm $i$

$x_{j}^{\beta}$ minimum required number of laborers at abattoir $j$

\section{Non-negative and binary decision variables}

$y_{\mathrm{i}}^{\alpha}=\left\{\begin{array}{l}1: \text { if farm } i \text { is located } \\ 0: \text { otherwise }\end{array}\right.$

$y_{j}^{\beta}=\left\{\begin{array}{l}1: \text { if abattoir } j \text { is located } \\ 0: \text { otherwise }\end{array}\right.$

\subsection{Optimization criteria}

The criteria functions are formulated as follows:

Minimum the total cost $\left(F_{l}\right)=$ costs of equipment and implementation for the RFID technology + transportations costs - labor costs saved after the RFID implementation as several manual operation activities were eliminated

$$
\begin{aligned}
& \operatorname{MinF}_{1}=\sum_{i \in I} C_{i}^{\alpha} y_{i}^{\alpha}+\sum_{j \in J} C_{j}^{\beta} y_{j}^{\beta}+\sum_{i \in I} \sum_{j \in J} T C_{i j}\left\lceil q_{i j} / W_{v}\right\rceil d_{i j} \\
& +\sum_{j \in J k \in K} \sum_{k} T C_{j k}\left\lceil q_{j k} / W_{v}\right\rceil d_{j k}-\sum_{i \in I} L C_{i}^{\alpha} x_{i}^{\alpha} h_{i}^{l \alpha}-\sum_{j \in I} L C_{j}^{\beta} x_{i}^{\beta} h_{i}^{l \beta}
\end{aligned}
$$

Maximum consumer satisfaction $\left(F_{2}\right)=$ the fulfillment of consumers 'demand

$$
\operatorname{MaxF}_{2}=\sum_{k=1}^{K}\left(\sum_{j=1}^{J} q_{i j} / D_{k}\right)
$$

Maximum product freshness $\left(F_{3}\right)=$ product quality of livestock shipped from farms to abattoirs + product freshness of meat pieces shipped from abattoirs to retailers

$$
\operatorname{MaxF}_{3}=\sum_{i=1}^{I} Q_{i j} y_{i}^{\alpha}+\sum_{j=1}^{J} F_{j k} y_{j}^{\beta}
$$

Maximum profits $\left(F_{4}\right)=$ return of investment for farms + return of investment for abattoirs

$$
\operatorname{MaxF}_{4}=\sum_{i \varepsilon I} \sum_{i \varepsilon J} R_{i}^{\alpha} x_{i j}^{u}+\sum_{j \in J} \sum_{k \in K} R_{j}^{\beta} x_{j k}^{v}
$$

\subsection{Defining the constraints}

Several constraints were defined after formulating the criteria functions. These constraints are grouped in different categories:

Capacity constraints: ensure the flow balance of products from farms to abattoirs and from abattoirs to retailers.

$$
\begin{array}{ll}
\sum_{i \in I} q_{i j} \leq C_{i}^{\alpha} \mathrm{x}_{i}^{\alpha} \quad & \forall \mathrm{j} \in \mathrm{J} \\
\sum_{j \in J} q_{\mathrm{jk}} \leq C_{\mathrm{j}}^{\beta} \mathrm{y}_{\mathrm{j}}^{\beta} ? \quad \forall \mathrm{k} \in K
\end{array}
$$

Demand constraints: ensure that all demands of abattoirs and retailers are fulfilled.

$$
\begin{array}{cc}
\sum_{\mathrm{i} \in \mathrm{I}} q_{\mathrm{ij}} \geq \mathrm{D}_{\mathrm{j}}^{\beta} & \forall \mathrm{j} \in \mathrm{J} \\
\sum_{\mathrm{j} \in \mathrm{J}} q_{\mathrm{jk}} \geq \mathrm{D}_{\mathrm{k}}^{\gamma} & \forall \mathrm{k} \in \mathrm{K} \\
\mathrm{D}_{\mathrm{j}}^{\beta} \geq \sum_{\mathrm{k} \in \mathrm{K}} q_{\mathrm{jk}} & \forall \mathrm{j} \in \mathrm{J}
\end{array}
$$

Working rate constraints: indicate the required number of laborers at farms and abattoirs.

$$
\begin{aligned}
& \sum_{j \in J} q_{i j} \leq x_{i}^{\alpha} \mathrm{R}_{i}^{1 \alpha} \quad \forall \mathrm{i} \in I \\
& \sum_{k \in K} q_{\mathrm{jk}} \leq x_{\mathrm{j}}^{\beta} \mathrm{R}_{\mathrm{j}}^{1 \beta} \quad \forall \mathrm{j} \in J
\end{aligned}
$$

Restriction constraints: restrict the decision variables to binary and non-negative.

$$
\begin{aligned}
& q_{i j}, q_{j k} \geq 0, \forall i, j, k ; s \\
& y_{i}^{\alpha}, y_{j}^{\beta} \in\{0,1\}, \forall i, j ;
\end{aligned}
$$

Finally, $\quad 0.75 \leq Q_{i j} \leq 1$ and $0.75 \leq F_{j k} \leq 1 \quad$ constraints which limit the quality percentage $(Q)$ and the freshness percentage $(F)$ to be between 0.75 and 1 (based on decision makers' preferences).

\section{Solution approach}

In this paper, three different solution approaches were examined to obtain three sets of Pareto solutions aiming to select the best one in terms of a solution value. Concisely, descriptions of the investigated solution approaches are presented in the next sub-section.

1) The developed approach: This approach transforms the multi-criteria model into a single-criterion model $\left(F_{s}\right)$ which is formulated by considering each criterion individually. This single-criteria model aims to minimize the scalarized differences between each criterion and its optimal value. Undesired deviations $\left(F_{d}\right)$ are proposed to be subtracted from $F_{s}$ with the aim to achieve more accurate criteria values. These values are close enough to Pareto optimal solutions which lead to a clear insight of a compromise solution between conflicting criteria for decision makers. The solution approach function $(\mathrm{F})$ can be formulated as follows:

$$
\operatorname{Min} F=F_{s}-F_{d}
$$




$$
\text { s.t. }\left\{\begin{array}{l}
\mu_{n}=\left[\frac{F_{n}-F_{n}^{\cdot}}{F_{n}^{*}}\right] \\
0 \geq w_{n} \geq 1 ; \sum_{n=1}^{4} w_{n}=1 ; \quad \mathrm{n}=(1,2,3,4)
\end{array}\right.
$$$$
\text { Set } w_{n}^{*}=\frac{w_{n} F_{n}^{\cdot}}{F_{n}^{*}-F_{n}} \text {, then }
$$$$
F_{d}=w_{1}^{*} F_{1}+w_{2}^{*} F_{2}+w_{3}^{*} F_{3}+w_{4}^{*} F_{4}
$$$$
=\frac{w_{1} F_{1}^{*}}{F_{1}^{*}-F_{1}} F_{1}+\frac{w_{2} F_{2}^{*}}{F_{2}^{*}-F_{2}} F_{2}+\frac{w_{3} F_{3}^{*}}{F_{3}^{*}-F_{3}} F_{3}+\frac{w_{4} F_{4}^{*}}{F_{4}^{*}-F_{4}} F_{4}
$$

Finally, based on the aforementioned procedures the developed approach's solution function can be written as follows

$$
\begin{aligned}
& \operatorname{Min} F=\left(w_{1} \mu_{1}-w_{2} \mu_{2}-w_{3} \mu_{3}-w_{4} \mu_{4}\right) \\
& -\left(\frac{w_{1} F_{1}^{\cdot}}{F_{1}^{\cdot}-F_{1}} F_{1}+\frac{w_{2} F_{2}^{\cdot}}{F_{2}^{\cdot}-F_{2}} F_{2}+\frac{w_{3} F_{3}^{\cdot}}{F_{3}^{\cdot}-F_{3}} F_{3}+\frac{w_{4} F_{4}^{\cdot}}{F_{4}^{\cdot}-F_{4}} F_{4}\right)
\end{aligned}
$$

The constraints contain equations (5)-(13) and (15).

2) Compromise programming approach: The compromise programming approach is its ability to achieve efficient points in a non-convex Pareto curve [15]. This method based on optimizing one criterion function and shifting the other to the constraint set to restricted to an assigned value (ந). The equivalent solution formula $(F)$ is presented as follow.

$$
\operatorname{Min} F_{1}
$$

Additional constraints:

$$
\begin{gathered}
F_{2} \geq \hbar_{1} \\
\left(F_{2}\right)^{\min } \leq \zeta_{1} \leq\left(F_{2}\right)^{\max } \\
F_{3} \geq \hbar_{2} \\
\left(F_{3}\right)^{\min } \leq \zeta_{2} \leq\left(F_{3}\right)^{\max } \\
F_{4} \geq \hbar_{3} \\
\left(F_{4}\right)^{\min } \leq \zeta_{3} \leq\left(F_{4}\right)^{\text {max }}
\end{gathered}
$$

In this paper, criterion function one is selected to be optimized (Eq.18) and shifting criterion functions two, three and four to be constraints; where $F_{2}, F_{3}$ and $F_{4}$ are greater or equal to $\hbar_{1}, \hbar_{2}$ and $\hbar_{3}$ respectively (Eq.19,21 and 23). A dramatic increasing to the $\zeta$ values (Eq.20, 22 and 24) yields more Pareto solutions.

3) Weighted Tchebycheff approach: This approach transforms the multi-criteria model into a single-criterion model $(F)$. This single-criteria model aims to minimize the distance between the ideal objective vector $\left(F^{*}\right)$ and the feasible objective surface [16]. The solution approach function $(F)$ can be formulated as follows:

$$
\operatorname{Min} F=\left(\sum_{i=1}^{4} l_{i}\left|F_{i}-F_{i}^{*}\right|^{p}\right)^{\frac{1}{p}}
$$

Subject to constraints defined in sub-section 3.3.

\section{Application and evaluation}

In order to demonstrate the application of the developed multi-criteria model and compare the performance of the proposed solution approaches, a case study is presented in this section. In the case study, the South East of London area encompasses 4 farms $(I), 7$ retailers $(K)$ and 4 abattoir $(J)$ suppliers. The given parameters were chosen in a defined range (based on assumption): equipment and implementation costs at farm $i\left(C_{i}^{\alpha}\right)=$ $4400 \mathrm{~K}-8800 \mathrm{~K}$ (GBP), equipment and implementation costs at abattoir $j\left(C_{j}^{\beta}\right)=1100 \mathrm{~K}-8.7 \mathrm{~K}$ (GBP), transportation costs from farm $i$ to abattoir $j$ and from abattoir $j$ to retailer $k\left(T C_{i j}^{m}, T C_{j k}^{n}\right)=20$ (GBP), supply capacity of farm $i\left(C_{\mathrm{i}}^{\alpha}\right)=2.5 \mathrm{~K}-4.4 \mathrm{~K}$, supply capacity of abattoir $j\left(C_{j}^{\beta}\right)=1.2 \mathrm{~K}-1.8 \mathrm{~K}$, demand of abattoir $j\left(\mathrm{D}_{\mathrm{j}}^{\beta}\right)=$ $800-1.3 \mathrm{~K}$, demand of retailer $k\left(\mathrm{D}_{\mathrm{j}}^{\beta}\right)=100-800 \mathrm{~K}$, travel distance from farm $i$ to abattoir $j\left(d_{i j}^{m}\right)=23-400$, travel distance from abattoir $j$ to retailer $k\left(d_{j k}^{n}\right)=110-162$, vehicle capacity $\left(W_{V}\right)=100$, quality percentage of livestock transported from farm $i$ to abattoir $j\left(Q_{i j}^{m}\right)=$ $0.75-1$, freshness percentage of meat pieces transported from abattoir $j$ to retailer $k\left(F_{j k}^{n}\right)=0.75-1$, minimum required number of working hours $h$ per laborer at farm $i$ and abattoir $j\left(h_{i}^{l \alpha}, h_{j}^{l \beta}\right)=1,800$ for each facility, labor cost per hour at farm ${ }^{i}$ and abattoir $j\left(L C_{i}^{\alpha}, L C_{j}^{\beta}\right)=6.5$ (GBP), working rate per labor $l$ at farm $i$ and abattoir $j$ $\left(R_{i}^{l \alpha}, R_{j}^{l \beta}\right)=50$ (item), profits per item at farm $i\left(P_{i}^{\alpha}\right)=$ $30(\mathrm{GBP})$ and profits per item at abattoirs $j\left(P_{j}^{\beta}\right)=25$ (GBP). It should be noted that the transportation distances between supply chains facilities were estimated using Google-Maps; also, the demand reported is the total demand over a one year period.

\subsection{Computational Results and comparison}

Using the above numerical data, the mixed-integer linear programming model described in Section 3.2 was solved using three approaches on a computer with corei5-CPU 2.60 GHz, RAM 4.00 GB, using the LINGO software.

Table 1 elucidates the four criteria solutions when solved individually. The total cost would be minimized to 194,180 GBP. If the criterion function one was only considered, while in this solution the criterion function 
two, three and four worsen to $75 \%, 8,885$ items and 363,080 GBP respectively. On the antithesis, if the second criterion function $\left(F_{2}\right)$ was only considered, consumer satisfaction would increase to $100 \%$. However, the total cost was increased to $491,000 \mathrm{GBP}$ in this solution. Considering the third criterion $\left(F_{3}\right)$ individually, product freshness would increase to 13,099 items with an increase in the total cost $(481,390 \mathrm{GBP})$, customer satisfaction (99\%) and profits (728,000 GBP). In this situation, the contradictory is manifested between these four criteria functions. However, moving to an improvement in consumer satisfaction and product freshness in the supply chain requires significantly higher cost investment. In Table 1 , it can be noticed that no solution is optimal i.e. it is impossible to obtain an optimal solution for the four criteria when solving them individually.

Table 1.The values for each criterion function when considered individually.

\begin{tabular}{lllll}
\hline $\begin{array}{l}\text { Criterion } \\
\text { function }\end{array}$ & $\operatorname{Min} F_{1}$ & $\operatorname{Max} F_{2}$ & $\operatorname{Max} F_{3}$ & $\operatorname{Max} F_{4}$ \\
\hline$F_{1}$ & 194,180 & 0.75 & 8,885 & 363,080 \\
$F_{2}$ & 491,000 & 1 & 13,099 & 728,000 \\
$F_{3}$ & 481,390 & 0.99 & 13,099 & 728,000 \\
$F_{4}$ & 491,000 & 0.99 & 13,099 & 728,000 \\
\hline
\end{tabular}

Table 2. Pareto solutions obtained by using three different approaches.

\begin{tabular}{|c|c|c|c|c|c|c|c|}
\hline Solution approach & $\#$ & $\begin{array}{c}\operatorname{Min}\left(F_{1}\right) \\
(G B P)\end{array}$ & $\begin{array}{c}\operatorname{Max}\left(F_{2}\right) \\
(\%)\end{array}$ & $\begin{array}{c}\operatorname{Max}\left(F_{3}\right) \\
\text { (items) }\end{array}$ & $\begin{array}{c}\operatorname{Max}\left(F_{4}\right) \\
(G B P)\end{array}$ & Open farms & Open abattoirs \\
\hline \multirow[t]{8}{*}{ The developed approach } & 1 & 194180 & 0.75 & 8885 & 363080 & 1001 & 0101 \\
\hline & 2 & 194180 & 0.75 & 8885 & 363080 & 1001 & 0101 \\
\hline & 3 & 194180 & 0.77 & 9411 & 507260 & 00011 & 0101 \\
\hline & 4 & 226150 & 0.815 & 10162 & 567860 & 1011 & 10011 \\
\hline & 5 & 253475 & 0.85 & 10876 & 596000 & 1111 & 1101 \\
\hline & 6 & 355336 & 0.9 & 11444 & 635240 & 1111 & 1011 \\
\hline & 7 & 392720 & 0.94 & 12131 & 666800 & 1111 & 0110 \\
\hline & 8 & 475660 & 0.99 & 13092 & 723620 & 1111 & 1101 \\
\hline \multirow[t]{8}{*}{ Compromise programming } & 1 & 194180 & 0.75 & 8885 & 363080 & 1001 & 0101 \\
\hline & 2 & 223257 & 0.776 & 9411 & 384534 & 1011 & 0101 \\
\hline & 3 & 248214 & 0.8 & 9937 & 406025 & 1011 & 0101 \\
\hline & 4 & 273171 & 0.826 & 10473 & 467927 & 0011 & 0101 \\
\hline & 5 & 300475 & 0.85 & 10989 & 529011 & 1011 & 1011 \\
\hline & 6 & 345228 & 0.91 & 11515 & 590501 & 1111 & 1101 \\
\hline & 7 & 382940 & 0.95 & 12041 & 651995 & 1111 & 1011 \\
\hline & 8 & 468475 & 1 & 13089 & 710610 & 1111 & 0110 \\
\hline \multirow[t]{8}{*}{ Weighted Tchebycheff } & 1 & 194180 & 0.75 & 8885 & 363080 & 1001 & 0101 \\
\hline & 2 & 194180 & 0.75 & 8885 & 363080 & 1001 & 0101 \\
\hline & 3 & 249231 & 0.78 & 8920 & 395060 & 1011 & 1111 \\
\hline & 4 & 288557 & 0.8 & 9808 & 4560100 & 1111 & 1111 \\
\hline & 5 & 338858 & 0.85 & 10414 & 470000 & 1111 & 1111 \\
\hline & 6 & 422451 & 0.91 & 11094 & 586880 & 1111 & 1101 \\
\hline & 7 & 539128 & 0.96 & 12376 & 620120 & 1111 & 1111 \\
\hline & 8 & 580471 & 0.99 & 13029 & 713480 & 1001 & 0101 \\
\hline
\end{tabular}

To this aim, three solution approaches were employed seeking the Pareto sets derived from cooptimizing the four contradicting criteria functions being considered (simultaneously) as minimizing the total cost $\left(F_{1}\right)$ in addition to maximizing consumer satisfaction $\left(F_{2}\right)$, product freshness $\left(F_{3}\right)$ and profits $\left(F_{4}\right)$. In aiming to obtain Pareto-optimal solutions using the three approaches: (i) for the developed solution approach, the values of the four criteria functions illustrated in Table 1 were given as optimal values $\left(F_{1}^{{ }_{1}}, F_{2}{ }_{2}, F^{{ }^{*}}{ }_{3}, F^{*}{ }_{4}\right)$ along with an assignment of different weight values $\left(w_{1}, w_{2}, w_{3}, w_{4}\right)$ for the solution function $F$ (Eq.17); (ii) for the compromise programming approach, eight $\hbar$ values were increasingly assigned from 8,885 to 13,099 with step 526 for criterion two (Eq.19), from 0.75 to 1 with step 0.25 for criterion three (Eq.21) and from 360,000 to 728,000 with step 46,000 for criterion four (Eq.23); and (iii) for the Weighted Tchebycheff approach, the values of the four criteria functions illustrated in Table I were given as optimal values $\left(F_{1}^{{ }^{*}}, F_{2}{ }_{2}, F_{3}{ }_{3}, F_{4}^{*}\right)$ along with an assignment of different values $\left(l_{1}, l_{2}, l_{3}, l_{4}\right)$ for the solution function $\mathrm{F}$ (Eq.25). The obtained three sets of
Pareto-optimal solutions using the three solution approaches are shown is Table 2. The third column of Table 2 represents the obtained values of the first criterion function $\left(F_{1}\right)$ in terms of GBP, obtained values of the second, third and fourth criterion functions $\left(F_{2}, F_{3}\right.$ and $F_{4}$ ) are presented in columns four, five and six respectively. The last two columns (right-end) correspond to the number of farms and abattoirs that should be established. For instance, solution\#4 for the first solution approach obtained by an assignment of $w_{1}=0.6, w_{2}=0.2, w_{3}=0.1$ and $w_{4}=0.1 ;$ accordingly, minimum total cost equals $226,150 \mathrm{GBP}$ while maximum consumer satisfaction equals $81.5 \%$, maximum product freshness equals 10,162 items and maximum profits equals 567,860 GBP. This solution consists an establishment of farms number one, three and four ( $\begin{array}{lll}1 & 0 & 1\end{array}$ 1) and abattoirs number one, three and four ( $\left.\begin{array}{llll}1 & 0 & 1 & 1\end{array}\right)$. As can also be observed in Table II, the Pareto optimal cannot get better in one criterion function except worsening its performance of the other three criterion functions. Fig. 2 illustrates a further comparison among the Pareto fronts obtained from the investigated solution approaches. 

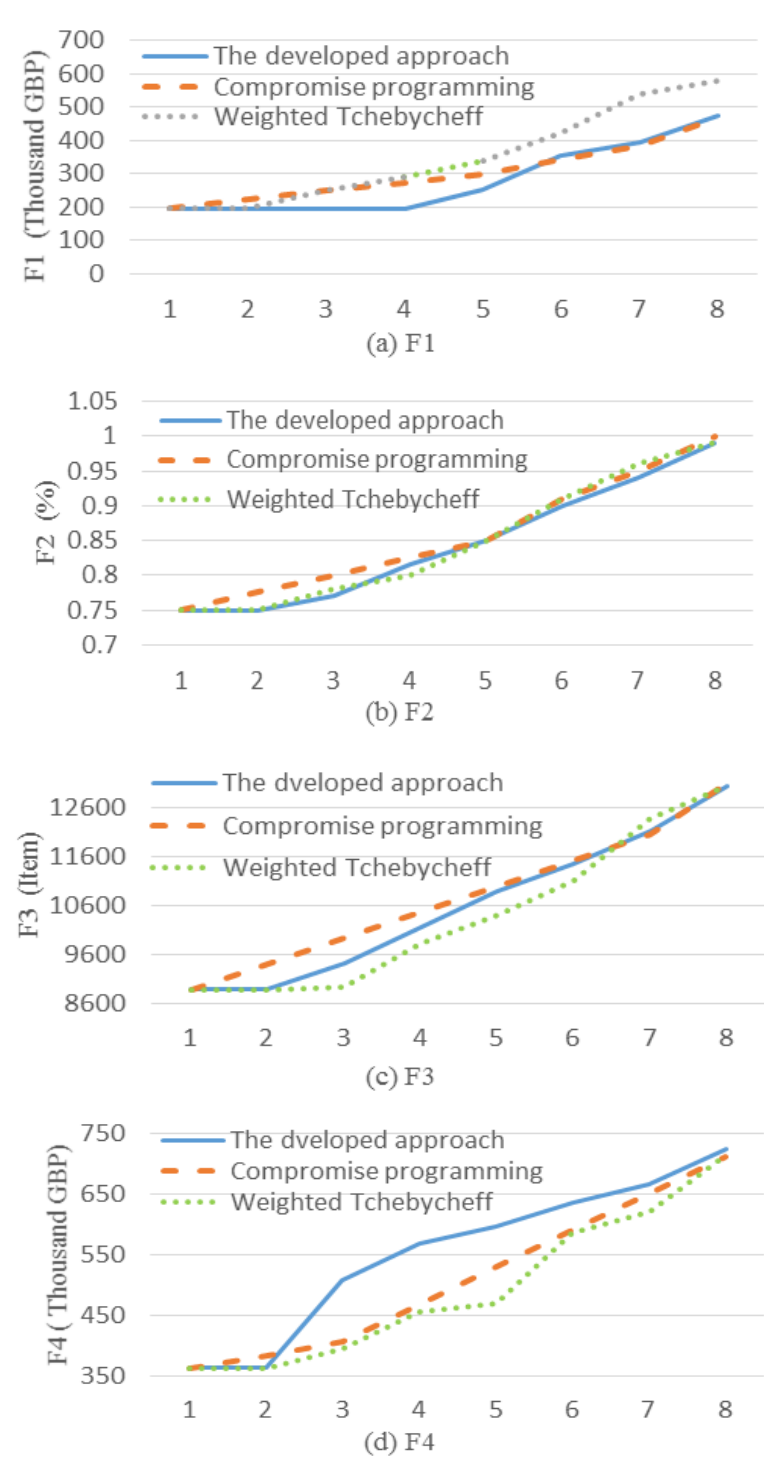

Figure 2. Pareto fronts using three solution approaches (a) F1, (b) F2, (c) F3, (d) F4.

It is noteworthy that in Table 2, the value of maximum profits for the eight solutions is more than the total costs which proves the feasibility in terms of economic costs of the proposed RFID-enabled meat supply chain after one year period for the RFID implementation.

\section{Conclusions}

This paper presents a study in investigating the economic feasibility of a proposed RFID-enabled monitoring system using a developed multi-criteria optimization model. The first criterion was the total cost; the second criterion was customer satisfaction which includes the fulfillment of consumers' demand; product freshness and profits were considered as third and fourth criteria respectively. The work findings show that high profits can still be achieved which proves that the RFID implementation in such a food supply chain is feasible in terms of economic costs. The direction for future research is to consider the effects of uncertain demand and costs regarding the investment evaluation.

\section{Acknowledgment}

The authors would like to express their gratitude to the Higher Committee for Education Development (HCED) in Iraq for the financial support in this study.

\section{References}

1. A. Mohammed, Q. Wang, Integrity of an RFIDenabled HMSC network, Pro. the $3^{\text {rd }}$ ICDEIS, China, 79-86 (2015)

2. A. Ahmed, Marketing of halal meat in the United Kingdom, Bri. F. J., 10, 655-670 (2008)

3. R.L. Meier, M.R. Williams, R.B. Singley, Supply Chain Management: Strategic Factors From The Buyers, Perspective, J. Ind. Tec., 20, 1-8 (2012)

4. W. Verbeke, P. Rutsaert. K. Bonne, L. Vermeir, Credence quality coordination and consumers' willingness-to-pay for certified halal labelled meat. Meat Sci., 95, 790-797 (2013)

5. S. Peattie, K. Peattie, A. Jamal, Influences on child nutrition: Bri. Muslims. Pub. H. Nutri., 9/7a, 181182 (2006)

6. M. Gen, R. Cheng, Genetic Algorithms and Engineering Design, (New York: John Wiley \& Sons 1997)

7. K. Deb, Multi-Objective Optimization using Evolutionary Algorithms, (New York, John Wiley \& Sons, 2001)

8. Z.J. Max Shen, M.S. Daskin, Trade-offs between customer service and cost in integrated supply chain design. Man. \& Ser. Op. Man., 7, 188-207 (2005)

9. R.G. Pandu, Multi-Objective Optimization: Techniques And Applications In Chemical Engineering (Advances in Process Systems Engineering). Singapore: Wor. Sci. Pub., (2009)

10. G. Barbarosoglu, d. Ozgur, Hierarchical design no fan integrated production and 2 echelon distribution system, Eur. J. Op. Res., 118, 464-84 (1999)

11. H. Sadjady, H. Davoudpour, Two-echelon, multicommodity supply chain network design with mode selection, lead-times and inventory costs, Com. Op. Res., 39, 1345-54 (2012)

12. H. Selim, C. Araz, I. Ozkarahan, Collaborative production-distribution planning in supply chain: a fuzzy goal programming approach, Tra. Res. Part E: Log. Tra. Rev., 44, 396-419 (2008)

13. J. Ferrio, J. Wassick, Chemical supply chain network optimization, Com. Che. Eng., 32, 2481-504 (2008)

14. U. Tuzkaya, S. Önüt, A holonic approach based integration methodology for transportation and warehousing functions of the supply network, Com. Ind. Eng., 56, 708-23 (2009)

15. V. Chankong, Y. Haimes, Multi-objective decision making theory and methodology (New York: Elsevier Science, 1983)

16. K. Miettinen, Nonlinear Multiobjective Optimization, (Ed. 1st . Springer US: Springer Science+Business Media New York, 1998) 